\title{
Atrial fibrillation in the patient undergoing mitral valve surgery: A once-in-a-lifetime opportunity
}

\author{
Marc Gillinov, MD, and Edward G. Soltesz, MD, MPH
}

\footnotetext{
From the Department of Thoracic and Cardiovascular Surgery, Cleveland Clinic, Cleveland, Ohio.

Disclosures: M.G. has served as a consultant to AtriCure, Medtronic, Edwards Lifesciences, CryoLife, and Abbott. E.G.S. has served as a consultant to Abbott.

Received for publication Sept 27, 2017; accepted for publication Sept 27, 2017; available ahead of print Oct 28, 2017.

Address for reprints: Marc Gillinov, MD, Department of Thoracic and Cardiovascular Surgery, Cleveland Clinic, Desk J4-1, 9500 Euclid Ave, Cleveland, OH 44195 (E-mail: gillinom@ccf.org).

J Thorac Cardiovasc Surg 2018;155:995-6

$0022-5223 / \$ 36.00$

Copyright (c) 2017 by The American Association for Thoracic Surgery

https://doi.org/10.1016/j.jtcvs.2017.09.125
}

Atrial fibrillation (AF) is present in $25 \%$ to $50 \%$ of patients seen for mitral valve surgery. Although it is likely that earlier referral of patients for mitral valve surgery will reduce this percentage, it is certain that surgeons will continue to see patients who have AF for mitral surgery. But will they treat them completely and correctly? Specifically, will they address the AF? With the left atrium opened to visualize the mitral valve, the surgeon has a once-in-alifetime opportunity to perform an ablation.

In this issue of the Journal, Ad and colleagues ${ }^{1}$ report their extensive experience and long-term results with surgical ablation in patients undergoing mitral valve surgery. In their introduction, they point out (1) that AF is associated with excess morbidity and reduced survival and (2) that surgical ablation of AF remains underused, with many surgeons simply choosing to ignore the AF at the time of mitral valve surgery. The results of this excellent series performed by experts in the field should encourage surgeons to do the right thing: ablate AF when performing mitral valve surgery.

\section{RESULTS OF ABLATION}

When considering the results of surgical ablation, 3 important questions come to mind, and Ad and colleagues ${ }^{1}$ answer all of them.

1. Is ablation safe? The answer is yes. Ad and colleagues ${ }^{1}$ report very low morbidity and mortality among the 473 patients in this series who underwent combined ablation and mitral valve surgery.

2. Does ablation provide good rhythm control? The answer is yes. In accordance with Heart Rhythm Society guidelines, Ad and colleagues ${ }^{1}$ collected excellent follow-up on their patients. At 7 years' follow-up, $66 \%$ of the patients were in sinus rhythm, and 55\% were both in sinus rhythm and free of antiarrhythmic medications.

3. Does ablation reduce the risk of stroke? Again, the answer is yes. In fact, with a $96.6 \%$ freedom from embolic stroke at 7 years, surgical ablation combined

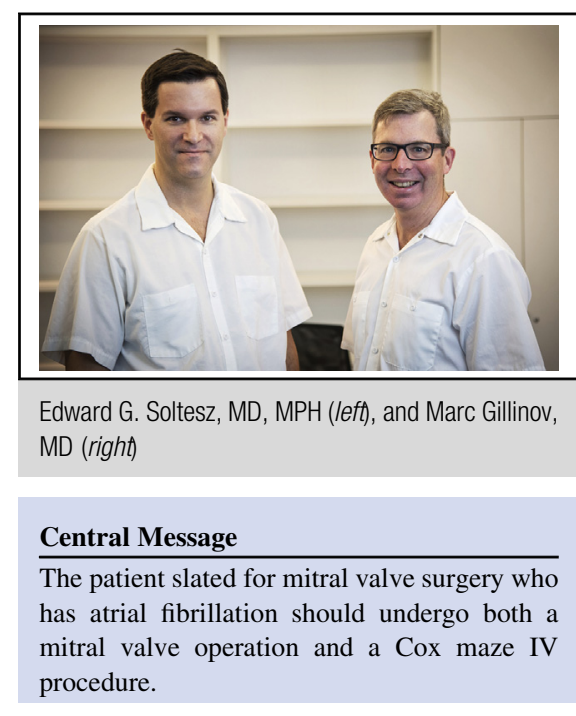

See Article page 983.

with management of the left atrial appendage represents the most effective strategy for stroke prevention in patients with AF.

These results point to a single conclusion: perform ablation in patients undergoing mitral valve operations who have $\mathrm{AF}$.

\section{THE OPERATION}

To this point, we have been using the term ablation. Now it is time to be more prescriptive. Ablation is a broad term, encompassing many different operations. In patients undergoing mitral valve operations who have AF, the correct ablation procedure is the Cox-maze III or IV. For most surgeons, this means an energy-assisted Cox maze IV. There is no need to seek shortcuts or eliminate lesions. The use of alternate energy sources makes the operation reasonably quick and carries minimal risk of bleeding. Which energy source is best? Ad and colleagues ${ }^{1}$ noted greater freedom from AF with cryothermy alone than with the combination of cryothermy and bipolar radiofrequency. This finding suggests the need for a randomized, controlled trial to compare these energy sources.

No matter which energy source is chosen, surgical expertise counts. In this series, the most experienced surgeons achieved the best results. This likely relates to nuances in surgical technique. Placing lesions in the correct locations and avoiding gaps in ablation lines enhance results. 
Although creation of the Cox maze IV lesion set does not pose technical challenges, failure to execute the operation properly jeopardizes results.

\section{FOLLOW-UP}

With their long-term follow-up, Ad and colleagues ${ }^{1}$ alert us to attrition of results with time. This highlights the need for continued follow-up and heart rhythm management after ablation. Return of AF, should it occur, does not signal failure; rather, it suggests the need for further treatment, which may entail antiarrhythmic medications or catheter ablation. Surgeons must remember, however, that AF treatment begins during the index operation, when, with the left atrium open, they have a once-in-a-lifetime opportunity to manage both the AF and the mitral valve.

\section{Reference}

1. Ad N, Holmes SD, Massimiano PS, Rongione AJ, Fornaresio LM. Long-term outcome following concomitant mitral valve surgery and Cox maze procedure for atrial fibrillation. J Thorac Cardiovasc Surg. 2018;155:983-94. 